\title{
Complementary and Alternative Medicine Use in Dermatology in the United States
}

\author{
Erin T. Landis, AB, Scott A. Davis, MA, Steven R. Feldman, MD, PhD, ${ }^{1-3}$ \\ and Sarah Taylor, MD, MPH, DABFM ${ }^{1}$
}

\begin{abstract}
Background: Complementary and alternative medicine (CAM) has an increasing presence in dermatology. Complementary therapies have been studied in many skin diseases, including atopic dermatitis and psoriasis. Objectives: This study sought to assess oral CAM use in dermatology relative to medicine as a whole in the United States, using the National Ambulatory Medical Care Survey.

Design: Variables studied include patient demographic characteristics, diagnoses, and CAM documented at the visits. A brief literature review of the top 5 CAM treatments unique to dermatology visits was performed.

Results: Most CAM users in both dermatology and medicine as a whole were female and white and were insured with private insurance or Medicare. Fish oil, glucosamine, glucosamine chondroitin, and omega-3 were the most common complementary supplements used in both samples.

Conclusions: CAM use in dermatology appears to be part of a larger trend in medicine. Knowledge of common complementary therapies can help dermatologists navigate this expanding field.
\end{abstract}

\section{Introduction}

$\mathbf{O}$ VER RECENT YEARS, COMPLEMENTARY and alternative medicine (CAM) therapies have become an increasingly visible part of American medicine. The National Health Interview Survey estimated that in 2007 alone, 38\% of adults in the United States used CAM. ${ }^{1}$ Although some alternative therapies are relatively noninvasive, with little risk of harm to the patient, others have known interactions and potential adverse effects when used alone or with conventional medicines. Many studies have therefore been undertaken to examine the effectiveness of these therapies, including natural and herbal products, food supplements, and mind-body therapies, with varying results in the clinical literature. Demographic studies of CAM use have revealed many trends, with major findings including increased use in women, those of higher socioeconomic status, and those with chronic disease. $^{2}$

Dermatology has seen its own trend toward complementary and alternative therapies. One review of seven surveys of dermatology patients revealed lifetime CAM use of 35\%$69 \%$. $^{3}$ Because interaction of these therapies with conventional dermatology therapies could potentially lead to adverse reactions, it is helpful for dermatologists to ask about any complementary or alternative therapies a patient may be using, as they would ask about conventional medications. For this purpose, an understanding of the complementary and alternative therapies they will encounter most is particularly useful. This study aimed to elucidate what complementary and alternative oral treatments are being used most in dermatology patients in the United States, what characteristics are most associated with use, and some applications of the most common oral CAM therapies according to the current literature.

\section{Materials and Methods}

To study CAM use in the United States, data from the National Ambulatory Medical Care Survey (NAMCS) were analyzed for variables of interest. The NAMCS is conducted by the National Center for Health Statistics (NCHS) as an ongoing data collection instrument designed to describe outpatient medical care in the United States. Data are collected by non-federally funded physicians who are randomly assigned to complete logs about their patients for a given week. Data collected include patient demographic characteristics, diagnoses, medications, supplements, and visit data. The NAMCS weights the data collected by using

${ }^{1}$ Center for Dermatology Research, Department of Dermatology, Wake Forest School of Medicine, Winston-Salem, NC.

${ }^{2}$ Department of Pathology, Wake Forest School of Medicine, Winston-Salem, NC.

${ }^{3}$ Department of Public Health, Wake Forest School of Medicine, Winston-Salem, NC. 
information about the "primary sampling unit" (county, contiguous counties, or standard metropolitan statistical area) and the number of physician practices in the region to project representative estimates of outpatient medical statistics in the United States. ${ }^{4,5}$

The NAMCS database was queried for CAM use in all specialties from 2006 to 2010, and the data were analyzed by such variables as patient age, sex, race, pay type, and medical specialty. For the purpose of this study, CAM medications were those denoted "alternative medicines," or category 218 in the Multum Lexicon database used by the NAMCS. The most frequently used medications denoted "complementary and alternative medications" were queried. After generation of this list, medications generally considered by the authors to be used off-label, but not fitting the category of alternative medicines, were excluded. The top 20 remaining CAM medications documented in the NAMCS were oral medications. Further calculations were done to determine how many patients used CAM per 100,000 population according to the 2010 U.S. census. Percentage of CAM use per specialty was also calculated, using NAMCS data for total visits to each specialty. The same analysis was carried out for patients seen by any specialty for skin disease. All data analysis was performed by using SAS software (SAS Institute, Cary, NC). A search using the PubMed search engine was then executed on the supplements unique to the top $10 \mathrm{CAMs}$ in visits to any specialty for skin disease to determine what clinical data exist about their utility. The study was declared exempt by the Wake Forest University Institutional Review Board.

\section{Results}

Demographic characteristics of CAM users among visits for all medical specialties and visits for skin disease were markedly similar in this sample. In both groups, the peak age for CAM use was 50-79 years (Table 1), and 56\% of each of these patient groups was female. Indeed, CAM use per 100,000 population increased with age in both samples to a peak of 140,000 visits documenting any CAM and 10,000 visits for skin disease in any specialty documenting CAM per 100,000 population for the 70-79 age group. This age peak was later than that for overall medication use, which peaked at age 45-55 years. White patients were far more likely to have documented CAM use, with 30,000 per 100,000 using any type of CAM, and 3000 per 100,000 using CAM in the context of a visit for skin disease. This was nearly three times the proportion of CAM use in both black and Asian or Pacific Islander populations, which had 9000 and 12,000 per 100,000 population using documented CAM, respectively. Each of these populations had 1000 or fewer per 100,000 documented as using CAM at visits for skin disease. In both overall medical visits and skin specific visits, private insurance and Medicare account for the vast majority (Table 1). In overall CAM visits, these two

Table 1. Demographic Characteristics of Patients Using Complementary and Alternative Medicine in All Medical Specialty and Skin Disease-Specific Visits

\begin{tabular}{|c|c|c|}
\hline Characteristic & $\begin{array}{l}\text { All medical specialty visits } \\
\text { (per 100,000 population) }\end{array}$ & $\begin{array}{l}\text { Skin disease-specific visits } \\
\text { (per 100,000 population) }\end{array}$ \\
\hline \multicolumn{3}{|l|}{ Sex } \\
\hline Female & $60,930,000(40,000)$ & $4,490,000(3000)$ \\
\hline Male & $48,640,000(30,000)$ & $3,660,000(2000)$ \\
\hline \multicolumn{3}{|l|}{ Patient age } \\
\hline $0-9 y$ & $2,140,000(5000)$ & $240,000(600)$ \\
\hline $10-19 y$ & $1,620,000(4000)$ & $170,000(400)$ \\
\hline $20-29 y$ & $3,100,000(7000)$ & $140,000(300)$ \\
\hline $30-39 y$ & $5,640,000(14,000)$ & $430,000(1000)$ \\
\hline $40-49 y$ & $11,490,000(30,000)$ & $970,000(2000)$ \\
\hline $50-59 y$ & $23,320,000(60,000)$ & $1,560,000(4000)$ \\
\hline $60-69 y$ & $25,960,000(90,000)$ & $1,890,000(6000)$ \\
\hline $70-79 y$ & $23,860,000(140,000)$ & $1,770,000(10,000)$ \\
\hline$\geq 80 y$ & $12,440,000(110,000)$ & $980,000(9000)$ \\
\hline \multicolumn{3}{|l|}{ Patient race } \\
\hline White only & $73,580,000(30,000)$ & $5,870,000(3000)$ \\
\hline Black only & $3,430,000(9000)$ & $370,000(1000)$ \\
\hline Asian or Pacific Islander & $1,840,000(12,000)$ & $130,000(800)$ \\
\hline American Indian or Alaska Native & $100,000(4000)$ & $40,000(1500)$ \\
\hline$>1$ race reported & $50,000(600)$ & $0(0)$ \\
\hline Unknown & $30,570,000(160,000)$ & $1,740,000(9000)$ \\
\hline \multicolumn{3}{|l|}{ Patient pay type } \\
\hline Private insurance & $55,060,000$ & $3,850,000$ \\
\hline Medicare & $43,560,000$ & $3,520,000$ \\
\hline Medicaid & $3,200,000$ & 270,000 \\
\hline Worker's compensation & 120,000 & 0 \\
\hline Self-pay & $2,520,000$ & 230,000 \\
\hline No charge & 270,000 & 10,000 \\
\hline Other/Unknown & $4,850,000$ & 270,000 \\
\hline
\end{tabular}


Table 2. Percentage of Patients Using Complementary and Alternative Medicine in All Medical Specialty and Skin Disease-Specific Visits

\begin{tabular}{lrc}
\hline $\begin{array}{l}\text { Medical specialty } \\
\text { documenting CAM use }\end{array}$ & $\begin{array}{c}\text { Number of visits }(\% \text { of visits } \\
\text { documenting CAM use by specialty) }\end{array}$ & $\begin{array}{c}\text { Number of visits }(\% \text { of skin disease visits } \\
\text { documenting CAM use by specialty) }\end{array}$ \\
\hline General/family practice & $24,150,000(2.2)$ & $2,120,000(1.9)$ \\
Internal medicine & $27,590,000(3.9)$ & $1,820,000(3.5)$ \\
Pediatrics & $3,140,000(0.50)$ & $270,000(0.40)$ \\
General surgery & $1,710,000(1.8)$ & $120,000(0.86)$ \\
Obstetrics/gynecology & $4,490,000(1.2)$ & $0(0)$ \\
Orthopedic surgery & $3,780,000(1.4)$ & $50,000(1.1)$ \\
Cardiovascular diseases & $12,180,000(7.6)$ & $170,000(12)$ \\
Dermatology & $2,210,000(1.2)$ & $2,040,000(1.3)$ \\
Urology & $2,560,000(2.5)$ & $0(0)$ \\
Psychiatry & $960,000(0.69)$ & $0(0)$ \\
Neurology & $1,460,000(2.1)$ & $50,000(1.8)$ \\
Ophthalmology & $7,280,000(2.5)$ & $560,000(3.7)$ \\
Otolaryngology & $1,290,000(1.3)$ & $70,000(1.5)$ \\
Other specialties & $15,010,000(2.5)$ & $720,000(1.8)$ \\
Oncology & $1,760,000(3.2)$ & $160,000(6.3)$ \\
\hline
\end{tabular}

CAM, complementary and alternative medicine.

pay types account for $90.0 \%$, while in visits for skin disease they account for $90.4 \%$ of visits.

The specialty most commonly documenting CAM use in both overall CAM and CAM in visits for skin disease was cardiovascular diseases, with $7.6 \%$ and $12 \%$ of visits, respectively, reporting CAM use (Table 2). Internal medicine was the specialty with the next highest rate of overall CAM reporting, with $3.9 \%$ of visits. In the skin disease-specific sample, oncology and ophthalmology had high rates of CAM use reported, at $6.3 \%$ and $3.7 \%$ of visits, respectively. Dermatology documented CAM in $1.2 \%$ of visits overall and in $1.3 \%$ of skin disease-specific visits (Table 2). In terms of visits for skin disease, dermatology, internal medicine, and family practice all had similar numbers of patients using CAM.

CAM use was documented in numerous skin conditions in this sample, with dermatitis of unspecified cause as the most common diagnosis (9.1\% of CAM skin disease diagnoses), followed by actinic keratosis $(8.0 \%)$ and unspecified disorder of the skin and subcutaneous tissues (4.6\%) (Table 3). CAM use in dermatology therefore does not appear to be confined to specific diagnoses.
In assessment of which individual CAM supplements were most used in all medical visits and specifically in dermatology visits, some entries overlapped, but some were also unique. In both samples, fish oil, glucosamine, and omega-3 accounted for the top 3 CAM therapies used (Tables 4 and 5). When combined with glucosamine chondroitin, these therapies accounted for $65.5 \%$ of overall visits with documented CAM use and $58.9 \%$ of CAM use in dermatology visits. Psorizide ${ }^{\circledR}$ (Plymouth Pharmaceuticals, Tulsa, OK) and Lactinex ${ }^{\circledR}$ (Becton Dickinson, Franklin Lakes, NJ) were the two most common unique CAM therapies in dermatology visits, each accounting for $7.2 \%$ and $4.3 \%$ of CAM dermatology visits, respectively. The other unique entries in the dermatology sample data include Herbavision $^{\mathrm{TM}}$ (Puritan's Pride, Oakdale, NY), and essential fatty acid (EFA) oil. The top 20 CAM therapies in patients diagnosed with skin disease as a first, second, or third diagnosis in all medical specialties further included L-lysine, St. John's wort, ginseng, and herbal drug (unspecified), which were not part of the top 20 overall CAMs across all specialties and diagnoses (Table 6).

Table 3. Top Dermatologic Diagnoses Associated with Complementary and Alternative Medicine Use, All Medical Specialties

\begin{tabular}{|c|c|c|c|}
\hline Diagnosis ${ }^{\mathrm{a}}$ & $\begin{array}{l}\text { Frequency } \\
(\%)\end{array}$ & $\begin{array}{c}\text { CAM skin disease } \\
\text { visits }(\%)\end{array}$ & $\begin{array}{l}\text { All CAM } \\
\text { visits }(\%)\end{array}$ \\
\hline Dermatitis of unspecified cause (692.9) & 740,000 & 9.1 & 0.7 \\
\hline Actinic keratosis (702.0) & 650,000 & 8.0 & 0.6 \\
\hline Unspecified disorder of skin and subcutaneous tissues (709.9) & 370,000 & 4.6 & 0.3 \\
\hline Other seborrheic keratosis (702.19) & 360,000 & 4.5 & 0.3 \\
\hline Malignant neoplasm of skin (173.9) & 350,000 & 4.3 & 0.3 \\
\hline Disturbance of skin sensation (782.0) & 270,000 & 3.3 & 0.2 \\
\hline Sarcoidosis (135.0) & 260,000 & 3.2 & 0.2 \\
\hline Herpes simplex without mention of complications (54.9) & 260,000 & 3.1 & 0.2 \\
\hline Other psoriasis $(696.1)$ & 250,000 & 3.0 & 0.2 \\
\hline Other acne (706.1) & 240,000 & 2.9 & 0.2 \\
\hline
\end{tabular}

${ }^{a}$ Values in parentheses are International Classification of Diseases, Ninth Revision, codes.

CAM, complementary and alternative medicine. 
Table 4. Top 20 Complementary and Alternative Medicines in 2006-2010, All Medical Specialties

\begin{tabular}{|c|c|c|}
\hline$C A M$ & $\begin{array}{l}\text { Frequency of } \\
\text { use (n) }\end{array}$ & $\begin{array}{c}C A M \\
\text { visits (\%) }\end{array}$ \\
\hline Fish oil & $34,880,000$ & 31.8 \\
\hline Glucosamine & $16,630,000$ & 15.2 \\
\hline Omega-3 & $12,070,000$ & 11.0 \\
\hline Glucosamine chondroitin & $8,270,000$ & 7.5 \\
\hline Lovaza $^{\circledR}$ & $5,860,000$ & 5.4 \\
\hline COQ-10 & $4,260,000$ & 3.9 \\
\hline Melatonin & $3,120,000$ & 2.8 \\
\hline Saw palmetto & $2,670,000$ & 2.4 \\
\hline Flaxseed oil & $2,230,000$ & 2.0 \\
\hline Lutein & $2,040,000$ & 1.9 \\
\hline Omacor $^{\circledR}$ & $1,880,000$ & 1.7 \\
\hline Flaxseed & $1,610,000$ & 1.5 \\
\hline Red yeast rice & $1,590,000$ & 1.4 \\
\hline Coenzyme Q10 & $1,560,000$ & 1.4 \\
\hline Garlic pill & $1,470,000$ & 1.3 \\
\hline Acidophilus & $1,330,000$ & 1.2 \\
\hline Osteo Bi-flex ${ }^{\circledR}$ & $1,210,000$ & 1.1 \\
\hline Chondroitin sulfate & $1,170,000$ & 1.1 \\
\hline Align ${ }^{\circledR}$ & $1,120,000$ & 1.0 \\
\hline Probiotica $^{\circledR}$ & 920,000 & 0.8 \\
\hline
\end{tabular}

CAM, complementary and alternative medicine.

\section{Brief Literature Review of the Top 5 Unique CAMs in Dermatology Visits}

The following section describes the most common CAMs found in the top 20 dermatology CAMs but not the top 20 CAMs across all medical specialties. A brief PubMed search

Table 5. Top 20 Complementary and Alternative MEDICINES IN 2006-2010, SPECIFIC to Dermatology Visits

\begin{tabular}{|c|c|c|}
\hline$C A M$ & $\begin{array}{l}\text { Frequency } \\
\text { of use (n) }\end{array}$ & $\begin{array}{c}\text { CAM dermatology } \\
\text { visits }(\%)\end{array}$ \\
\hline Fish oil & 730,000 & 33.1 \\
\hline Omega-3 & 260,000 & 12.0 \\
\hline Glucosamine & 190,000 & 8.4 \\
\hline Psorizide $^{\circledR a}$ & 160,000 & 7.2 \\
\hline Glucosamine chondroitin & 120,000 & 5.4 \\
\hline Lactinex $^{\circledR a}$ & 100,000 & 4.3 \\
\hline Herbavision $^{\mathrm{TM} a}$ & 90,000 & 4.1 \\
\hline EFA oil $^{\mathrm{a}}$ & 70,000 & 3.3 \\
\hline Flex Protex ${ }^{\mathrm{TM} a}$ & 70,000 & 3.3 \\
\hline Reishi $^{\mathrm{a}}$ & 70,000 & 3.3 \\
\hline Saw palmetto & 70,000 & 3.1 \\
\hline Melatonin & 60,000 & 2.6 \\
\hline Skinceuticals Phloretin ${ }^{\circledR}$ & 40,000 & 2.0 \\
\hline Policosanol $^{\mathrm{a}}$ & 40,000 & 2.0 \\
\hline Carnitine $^{\mathrm{a}}$ & 40,000 & 1.8 \\
\hline Primrose oil ${ }^{\mathrm{a}}$ & 40,000 & 1.8 \\
\hline Acunol $^{\circledR a}$ & 40,000 & 1.8 \\
\hline Flaxseed oil & 40,000 & 1.6 \\
\hline Chondroitin sulfate & 30,000 & 1.6 \\
\hline Cinnamon & 30,000 & 1.6 \\
\hline
\end{tabular}

${ }^{\mathrm{a}}$ Unique to the top 20 medications prescribed for this dermatology visit-specific sample and do not appear in the corresponding data for top $20 \mathrm{CAM}$ medications prescribed overall.

CAM, complementary and alternative medicine; EFA, essential fatty acid.
Table 6. Top 20 Complementary and Alternative Medicines in 2006-2010, at Visits with Skin Disease as First, Second, or Third Diagnosis in All Medical Specialties

\begin{tabular}{|c|c|c|}
\hline$C A M$ & $\begin{array}{l}\text { Frequency } \\
\text { of use (n) }\end{array}$ & $\begin{array}{c}\text { CAM } \\
\text { visits }(\%)\end{array}$ \\
\hline Fish oil & $2,560,000$ & 31.4 \\
\hline Glucosamine & $1,150,000$ & 14.1 \\
\hline Glucosamine chondroitin & 540,000 & 6.6 \\
\hline Omega-3 & 510,000 & 6.3 \\
\hline Melatonin & 410,000 & 5.0 \\
\hline $\mathrm{L}-\mathrm{Lysine}^{\mathrm{a}}$ & 310,000 & 3.8 \\
\hline Lovaza $^{\circledR}$ & 300,000 & 3.6 \\
\hline Osteo Bi-flex ${ }^{\circledR}$ & 220,000 & 2.7 \\
\hline Lutein & 170,000 & 2.1 \\
\hline Psorizide $^{\circledR a}$ & 160,000 & 2.0 \\
\hline St. John's wort ${ }^{\mathrm{a}}$ & 150,000 & 1.9 \\
\hline Saw palmetto & 140,000 & 1.8 \\
\hline COQ-10 & 140,000 & 1.7 \\
\hline Lactinex $^{\circledR a}$ & 140,000 & 1.7 \\
\hline Ginseng ${ }^{\mathrm{a}}$ & 100,000 & 1.2 \\
\hline Herbal drug (unspecified) ${ }^{a}$ & 90,000 & 1.2 \\
\hline Herbavision & 90,000 & 1.1 \\
\hline Chondroitin sulfate & 90,000 & 1.1 \\
\hline Garlic pill & 80,000 & 0.97 \\
\hline Remifemin ${ }^{\mathrm{a}}$ & 80,000 & 0.96 \\
\hline
\end{tabular}

${ }^{\mathrm{a}}$ Unique to the top 20 medications prescribed for this skin disease visit-specific sample and do not appear in the corresponding data for top $20 \mathrm{CAM}$ medications prescribed overall.

CAM, complementary and alternative medicine.

was performed to better describe the proposed indications for each of the following in addition to the current available evidence base for their use.

\section{Psorizide $^{\circledR}$}

According to its official website, Psorizide ${ }^{\circledR}$ Forte is a prescription homeopathic medication designed to improve the symptoms of contact dermatitis, dyshidrotic eczema, and psoriasis. ${ }^{6}$ According to the medication's package insert, this product contains nickel sulfate, potassium bromide, and fumaric acid as active ingredients. ${ }^{6}$ The product has not been evaluated by the FDA, but according to one source, one 650-mg capsule contains $1 \mathrm{mg}$ of nickel sulfate, $15 \mathrm{mg}$ of potassium bromide, and $30 \mathrm{mg}$ of fumaric acid. ${ }^{7}$

Several studies have reported the effectiveness of a similar formulation or one of its components in skin disease. An early randomized crossover study of nickel dibromide showed statistically significant change in the patients' psoriasis after 12 weeks of use. ${ }^{8}$ One randomized controlled trial of a formulation similar to this product in seborrheic dermatitis showed improvement in the treatment group after 10 weeks compared with placebo, based on severity and area affected. ${ }^{9}$ This study further used a crossover design, which showed improvement in the control group upon transitioning to the experimental therapy. ${ }^{9}$ The manufacturer notes no known contraindications other than allergy to one of the medication components and reports no known drug interactions, but it has provided information on metal toxicity syndromes. ${ }^{6}$

Nevertheless, examination of each component individually in the literature shows several potential adverse effects 
with this treatment. Nickel is a well-known allergen, particularly in contact dermatitis, but systemic nickel allergy syndrome has also been studied in the literature, and results in gastrointestinal or widespread cutaneous reaction. ${ }^{10}$ Also of concern is potential acute metal toxicity. One study revealed a median lethal dose for acute toxicity of $362 \mathrm{mg} / \mathrm{kg}$ body weight for nickel sulfate hexahydrate, the second lowest of the 11 distinct nickel compounds tested. Nickel sulfate is therefore one of the most concerning nickel compounds for acute toxicity, although even this toxicity risk is thought to be very low. ${ }^{11}$ Of perhaps more concern than acute toxicity is the observation that nickel sulfate exposure, as in nickel refiners, has been correlated with an elevated risk of cancer, particularly nasal, stomach, and lung cancers. ${ }^{12}$ Earlier animal studies also showed bone marrowsuppressive effects of systemic nickel sulfate in mice models, with nickel accumulation in the kidneys. ${ }^{13}$ Another component of this medication, potassium bromide, has meanwhile been noted to result in bromoderma, characterized by severe papular and pustular eruptions, in children taking it for epilepsy. ${ }^{14}$ Finally, fumaric acid has been described in the literature as causing a cutaneous flushing reaction. ${ }^{15}$

Thus, although some limited trials suggest efficacy in treatment of psoriasis and seborrheic dermatitis, the individual components of this homeopathic medication cannot be described as innocuous, particularly in large doses or over the long term. It is worth noting that it is uncertain exactly how much of each component is in this medication; therefore, the degree to which these adverse effects should be expected is unclear. On the basis of its homeopathic nature, each component is probably quite diluted; thus, these adverse effects are expected to be quite rare.

\section{Lactinex $^{\mathbb{R}}$}

This probiotic preparation includes Lactobacillus acidophilus and L. bulgaricus strains. It has been studied in trials as prophylaxis against some antibiotic-associated diarrheas. ${ }^{16}$ More recently, Lactobacillus strains have been studied in atopic dermatitis and been found to improve clinical symptoms and disease-specific quality of life. ${ }^{17}$ Probiotics and prebiotics have also been studied in children with atopic dermatitis and have been successful in symptom reduction. ${ }^{18}$ One study of probiotics in nonscalp psoriasis, however, showed no benefit. ${ }^{19}$ The success seen in some studies may be due to the brain-gut-skin theory, which hypothesizes that the bacterial flora in a patient's gut may cause inflammation and predispose to inflammatory conditions of the skin and other organ systems. ${ }^{20}$ Therefore, by altering the gut flora of the patient with probiotics, we may theoretically be able to alter inflammatory states and modify disease processes. Adverse effects from probiotics are very rare, but they may have benefits as noted in the literature, such as improvement in antibiotic-associated diarrhea. ${ }^{21}$

\section{Herbavision $^{\mathrm{TM}}$}

According to the official website of this product's producer, this compound contains bilberry extract and lutein, designed to support healthy vision and provide antioxidants. $^{22}$ In the complementary medicine literature, the indications for bilberry include vision problems, vascular disease, inflammatory disease, and diabetes, with effects thought to be mediated by the antioxidant anthocyanoside flavonoids found in the fruit. ${ }^{23}$ In one study of keratinocytes, administration of bilberry extract decreased reactive oxygen species, lipid peroxidation, and overall keratinocyte damage resulting from ultraviolet $\mathrm{A}$ light. ${ }^{24}$ Other antioxidant studies in patients have shown improved skin texture, with decreased scaling and roughness seen among in patients using antioxidants. ${ }^{25}$ Because bilberry is a food product, many claim it is generally safe, with little chance of toxicity or drug interaction. ${ }^{23}$ Multiple literature searches in PubMed did not reveal any significant adverse effects from bilberry or lutein use.

\section{EFA oil}

EFA oil has been used in many clinical trials among patients with atopic dermatitis. Like fish oil, EFA oil contains omega-3 fatty acids, which are thought to be anti-inflammatory. ${ }^{26}$ One meta-analysis of 11 clinical trials showed no significant improvement in atopic dermatitis symptoms or severity. ${ }^{27}$ However, another meta-analysis specific to borage oil, which has a higher gamma-linolenic acid component than many of its counterparts, stated that investigators were unable to exclude a small effect that could warrant use of the supplement in specific patients. ${ }^{28}$ Because EFA oil can be considered a dietary supplement, similar to fish oil, it is considered to be generally safe; certain specific isomers of linoleic acid have rarely been associated with decreased high-density lipoprotein and insulin resistance. ${ }^{29,30}$

\section{Discussion}

From the NAMCS data used in this study, it appears that CAM use in dermatology is common. A total of roughly $8,150,000$ patients with skin disease were projected to have used CAM in the 5-year study period, and these patients had demographic characteristics similar to those of patients using CAM overall, including predominance in white patients, women, those aged 50-79 years, and those insured through private insurance or Medicare. Much of this demographic information fits with epidemiologic data in the general CAM literature and shows that CAM in dermatology appears to be a part of the overall CAM trend, rather than a unique phenomenon.

CAM use in dermatologic conditions was not limited to specific disease subtypes but instead was spread across many disorders, with the highest individual proportion going to unspecified dermatitis. This most common category accounted for only $9.1 \%$ of overall skin disorder CAM visits. The widespread nature of CAM use further underscores how pervasive a practice it has become, and the necessity for awareness of potential CAM use in patients in whom there could be adverse effects or drug interactions.

Many of the CAM supplements used in patients with skin disease were identical to those used most often in all visits, with fish oil, glucosamine, and omega-3 making up the top three supplements in both categories. The use of these agents for general health and joint effects in patients who happen to have presented at the recorded visit for skin disease cannot be excluded and seems likely given their widespread use in the general CAM population. 
The top four unique supplements for skin disease visits among the top 20 included Psorizide ${ }^{\circledR}$, Lactinex ${ }^{\circledR}$, Herbavision $^{\text {TM }}$, and EFA oil, which have potential applications in atopic dermatitis, psoriasis, and skin damage. Although the literature presents a mixed picture of the effectiveness of these agents, several studies of components in Lactinex ${ }^{\circledR}$ and Psorizide ${ }^{\circledR}$ suggest some improvement in skin disease symptoms and severity, while Herbavision ${ }^{\mathrm{TM}}$ and EFA oil have theoretical effects and small effects in some studies. Despite this, the paucity of studies regarding their effectiveness and adverse effect profiles cause a conflict for dermatologists who are interested in incorporating CAM therapies into the treatment of their patients. Many patients will come to use CAM on their own, without the advice of their physician or an alternative medicine provider. Thus, use of CAM therapies should be elicited by dermatologists so they can be better prepared to address their effects in patients and be vigilant for potential adverse effects as these therapies are investigated further.

This study has several limitations, largely due to the use of the NAMCS as the data source. Because of the survey design, it is unclear whether CAM use at this visit was new or ongoing, or whether it was initiated by the patient, recommended by the charting physician, or recommended by a separate physician or provider. Similarly, although part of the data analysis of this study was limited to visits for skin disease, it cannot be determined from the data set whether the supplements noted were initiated for skin disease, other health problems, or general wellness. Limitations in the data collection may also have led to underestimation of CAM use, if the charting physician did not elicit this or the patient did not volunteer that they were using CAM therapies. Furthermore, because the NAMCS is limited to physicians and does not survey other alternative medicine providers, overall CAM use in the population is very likely underestimated by this study.

In conclusion, CAM use in dermatology is a common practice in the United States, as it now is in the medical field overall. Many agents have been studied in both the complementary and the conventional literature in an attempt to elucidate the effectiveness of many of these agents. Although some appear to produce clinical improvement, there is a paucity of clinical trials and information on potential adverse effects, long-term use, and drug interactions. Because of the widespread use of these agents, it is recommended that dermatologists ask their patients about CAM use in order to consider potential adverse effects and interactions with the conventional treatments they prescribe.

\section{Author Disclosure Statement}

The Center for Dermatology Research is supported by an unrestricted educational grant from Galderma Laboratories, L.P. Dr. Feldman is a consultant and speaker for Galderma, Stiefel/GlaxoSmithKline, Abbott Labs, Warner Chilcott, Janssen, Amgen, Photomedex, Genentech, BiogenIdec, and Bristol-Myers Squibb. Dr. Feldman has received grants from Galderma, Astellas, Abbott Labs, Warner Chilcott, Janssen, Amgen, Photomedex, Genentech, BiogenIdec, Coria/ Valeant, Pharmaderm, Ortho Pharmaceuticals, Aventis Pharmaceuticals, Roche Dermatology, 3M, Bristol-Myers
Squibb, Stiefel/GlaxoSmithKline, Novartis, Medicis, Leo, HanAll Pharmaceuticals, Celgene, Basilea, and Anacor and has received stock options from Photomedex. He is owner of www.DrScore.com and a founder of Causa Research. Ms. Landis, Mr. Davis, and Dr. Taylor have no conflicts to disclose.

\section{References}

1. National Center for Complementary and Alternative Medicine. What is complementary and alternative medicine [homepage on the Internet]? Online document at: http:// nccam.nih.gov/health/whatiscam Accessed February 21, 2013.

2. Straus SE. Herbal medicines-what's in the bottle? N Engl J Med 2002;19;347:1997-1998.

3. Ernst E. The usage of complementary therapies by dermatological patients: a systematic review. Br J Dermatol 2000;142:857-861.

4. Fleischer AB Jr, Feldman SR, Bradham DD. Officebased physician services provided by dermatologists in the United States in 1990. J Invest Dermatol 1994; 102:93-97.

5. Fleischer AB Jr, Feldman SR, White RE, Leshin B, Byington R. Procedures for skin diseases performed by physicians in 1993 and 1994: analysis of data from the National Ambulatory Medical Care Survey. J Am Acad Dermatol 1997;37(5 Pt 1):719-724.

6. Plymouth Pharmaceuticals. Psorizide Forte [homepage on Internet]. 2013. Online document at: http://www.plymouth pharmaceuticals.com/files/5913/6207/9173/PForte_pinsert_ 0107.pdf Accessed February 24, 2013.

7. Daily Med. Psorizide Forte [homepage on Internet]. 2013. Online document at: http://dailymed.nlm.nih.gov/dailymed/ lookup.cfm?setid=7896794a-60bd-4dfa-abfe-aa29aaa6f74d Accessed July 19, 2013.

8. Smith SA, Young TR, Winsjansen E, Baker AE, Williams $\mathrm{JH}$, Jr. Improvement of psoriasis vulgaris with oral nickel dibromide. Arch Dermatol 1997;133:661-663.

9. Smith SA, Baker AE, Williams JH. Effective treatment of seborrheic dermatitis using a low dose, oral homeopathic medication consisting of potassium bromide, sodium bromide, nickel sulfate, and sodium chloride in a double-blind, placebo-controlled study. Altern Med Rev 2002;7:59-67.

10. Ricciardi L, Carni A, Loschiavo G, et al. Systemic nickel allergy: oral desensitization and possible role of cytokines interleukins 2 and 10. Int $\mathrm{J}$ Immunopathol Pharmacol 2013;26:251-257.

11. Henderson RG, Cappellini D, Seilkop SK, Bates HK, Oller AR. Oral bioaccessibility testing and read-across hazard assessment of nickel compounds. Regul Toxicol Pharmacol 2012;63:20-28.

12. Anttila A, Pukkala E, Aitio A, Rantanen T, Karjalainen S. Update of cancer incidence among workers at a copper/ nickel smelter and nickel refinery. Int Arch Occup Environ Health 1998;71:245-250.

13. Dieter MP, Jameson CW, Tucker AN, et al. Evaluation of tissue disposition, myelopoietic, and immunologic responses in mice after long-term exposure to nickel sulfate in the drinking water. J Toxicol Environ Health 1988;24:357-372.

14. Anzai S, Fujiwara S, Inuzuka M. Bromoderma. Int J Dermatol 2003;42:370-371.

15. Hanson J, Gille A, Offermanns S. Role of HCA(2) (GPR109A) in nicotinic acid and fumaric acid ester-induced effects on the skin. Pharmacol Ther 2012;136:1-7. 
16. Tankanow RM, Ross MB, Ertel IJ, Dickinson DG, McCormick LS, Garfinkel JF. A double-blind, placebocontrolled study of the efficacy of Lactinex in the prophylaxis of amoxicillin-induced diarrhea. DICP 1990;24: 382-384.

17. Drago L, Iemoli E, Rodighiero V, Nicola L, De VE, Piconi S. Effects of Lactobacillus salivarius LS01 (DSM 22775) treatment on adult atopic dermatitis: a randomized placebocontrolled study. Int J Immunopathol Pharmacol 2011;24: 1037-1048.

18. Passeron T, Lacour JP, Fontas E, Ortonne JP. Prebiotics and synbiotics: two promising approaches for the treatment of atopic dermatitis in children above 2 years. Allergy 2006;61:431-437.

19. Kaur M, Conde J, Willard JD, et al. A randomized, doubleblind clinical trial of a probiotic nutritional intervention in the treatment of mild to moderate non-scalp psoriasis. Psoriasis Forum 2007;13:12-15.

20. Bowe WP, Logan AC. Acne vulgaris, probiotics and the gut-brain-skin axis_-back to the future? Gut Pathog 2011; 3:1-3.

21. Hempel S, Newberry SJ, Maher AR, et al. Probiotics for the prevention and treatment of antibiotic-associated diarrhea: a systematic review and meta-analysis. JAMA 2012;307: 1959-1969.

22. Puritan's Pride. Herbavision with Lutein and Bilberry [homepage on Internet]. 2013. Online document at: http:// www.puritan.com/eye-health-003/herbavision-with-luteinand-bilberry-004755. Accessed March 10, 2013.

23. Monograph. Vaccinium myrtillus (bilberry). Altern Med Rev 2001;6:500-504.

24. Svobodova A, Rambouskova J, Walterova D, Vostalova J. Bilberry extract reduces UVA-induced oxidative stress in
HaCaT keratinocytes: a pilot study. Biofactors 2008;33: 249-266.

25. Heinrich U, Tronnier H, Stahl W, Bejot M, Maurette JM. Antioxidant supplements improve parameters related to skin structure in humans. Skin Pharmacol Physiol 2006; 19:224-231.

26. Maroon JC, Bost JW. Omega-3 fatty acids (fish oil) as an anti-inflammatory: an alternative to nonsteroidal antiinflammatory drugs for discogenic pain. Surg Neurol 2006; 65:326-331.

27. van Gool CJ, Zeegers MP, Thijs C. Oral essential fatty acid supplementation in atopic dermatitis-a meta-analysis of placebo-controlled trials. Br J Dermatol 2004;150:728-740.

28. Foster RH, Hardy G, Alany RG. Borage oil in the treatment of atopic dermatitis. Nutrition 2010;26:708-718.

29. Mougios V, Matsakas A, Petridou A, et al. Effect of supplementation with conjugated linoleic acid on human serum lipids and body fat. J Nutr Biochem 2001;12:585-594.

30. Riserus U, Arner P, Brismar K, Vessby B. Treatment with dietary trans10cis 12 conjugated linoleic acid causes isomer-specific insulin resistance in obese men with the metabolic syndrome. Diabetes Care 2002;25:1516-1521.

Address correspondence to: Steven R. Feldman, MD, PhD Center for Dermatology Research Department of Dermatology Wake Forest University School of Medicine Medical Center Boulevard Winston-Salem, NC 27157-1071

E-mail: sfeldman@wakehealth.edu 